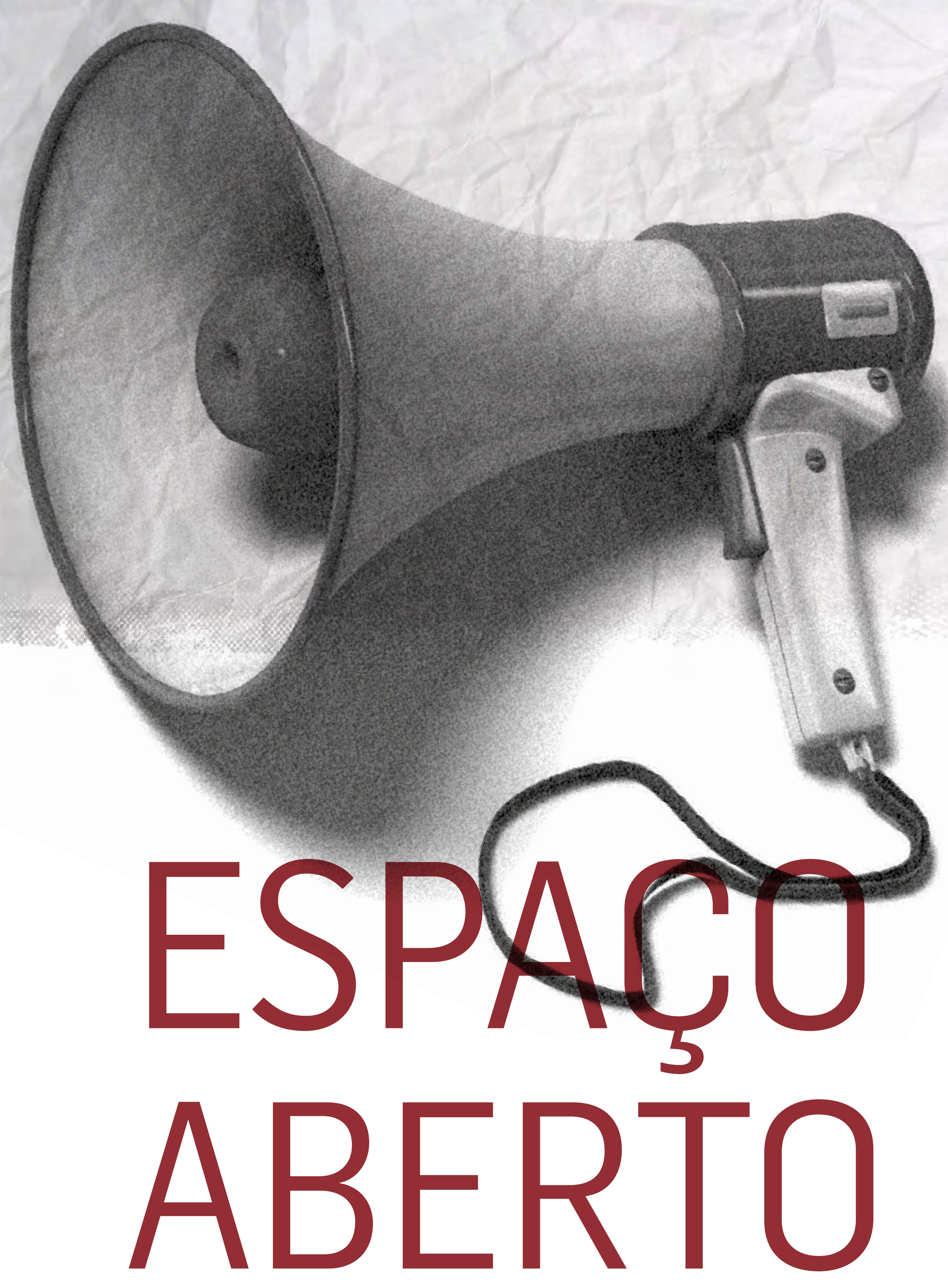




\title{
Impresso versus digital: \\ uma reflexão sobre a transição do meio impresso
}

\author{
Printed versus digital: \\ a reflection on the transition of the printed means
}

Impreso versus digital:

una reflexión sobre la transición del medio impreso

Maria Aparecida Ferrari

- $\quad$ Doutora e mestre em Ciências da Comunicação pela Escola de Comunicações e Artes da Universidade de São Paulo (ECA-USP)

- $\quad$ Graduada em Ciências Sociais pela USP e em Relações Públicas pela Faculdade Anhembi-Morumbi

- $\quad$ Docente na graduação e na pós-graduação do Departamento de Relações públicas, Propaganda e Turismo da ECA-USP

- $\quad$ Foi diretora editorial da Associação Brasileira de Pesquisadores de Comunicação Organizacional e de Relações públicas (Abrapcorp), na gestão 2012-2014

- $\quad$ Coautora dos livros Relações públicas: teoria, contexto e relacionamentos, Relaciones públicas: naturaleza, función y gestión de las organizaciones contemporáneas e Gestión de relaciones públicas para el éxito de las organizaciones

- $\quad$ E-mail: maferrar@usp.br

\section{Carmen Valéria de Andrade Barreto}

- $\quad$ Graduada em Jornalismo pelas Faculdades Integradas Alcântara Machado (Fiam)

- $\quad$ Especialista em Gestão Estratégica em Comunicação Organizacional e Relações Públicas pela ECA-USP

- $\quad$ Dedica-se à área de comunicação há 28 anos, tendo atuado na Rede Bandeirantes como produtora e pauteira de programas de televisão

- $\quad$ Desde 1990 atua no mercado editorial, como assessora de imprensa e gerente de comunicação

- $\quad$ E-mail: carmenabarreto@gmail.com 


\section{Resumo}

A presente pesquisa pretende abordar algumas contribuições teóricas e práticas para verificar como, no presente momento, tem se dado a transição do meio impresso para o digital entre jovens universitários e líderes de opinião da área editorial e da comunicação. Para tanto, as autoras fazem inicialmente uma reconstituição da trajetória do texto impresso até chegar ao meio digital. 0 objetivo é entender como as pessoas estão se relacionando (ou não) e como percebem essa transição para a plataforma digital. Dados sobre uma amostra com seis líderes de opinião e, aproximadamente, cem jovens universitários foram coletados para cumprir com o objetivo do estudo. 0 objetivo era conhecer a opinião da amostra, identificar as tendências em relação à transição do impresso para o digital e captar suas percepções com relação à tecnologia e às tendências que se avizinham no contexto brasileiro.

PALAVRAS-CHAVE: COMUNICAÇÃO • RELAÇÕES PÚBLICAS • MEIOS DIGITAIS • INCLUSÃO DIGITAL • TECNOLOGIAS DIGITAIS • LIVROS DIGITAIS (E-BOOKS).

\section{Abstract}

This study aims at addressing some theoretical and practical contributions to verify how the transition from printed media to digital media is taking among university students and opinion makers of editorial and communication area at the present moment. To achieve this the authors initially reconstruct the route from printed text to digital medium. The objective is of understanding how people are (or not) relating with each other and how they perceive this transition to a digital platform. Data on a sampling survey conducted with six opinion leaders and around one hundred university students were collected to fulfill the purpose of the study. The objective was to know the opinion of this sample, to identify the trends in relation to the transition from printed to digital media and to obtain their perception of the technology and of the trends that lie ahead in the Brazilian context.

\section{KEYWORDS: COMMUNICATION • PUBLIC RELATIONS • DIGITAL MEDIA •DIGITAL INCLUSION •DIGITAL BOOKS (E-BOOKS).}

\section{Resumen}

Esta investigación tiene como objetivo ofrecer aportes teóricos y prácticos para ver cómo, en la actualidad, se ha dado la transición del medio impreso al digital entre jóvenes universitarios y líderes de opinión en el campo de la edición y de la comunicación. Para este fin, las autoras inicialmente hacen una reconstrucción de la trayectoria del texto impreso hasta llegar al medio digital. El objetivo es entender cómo las personas se están relacionando (o no) y cómo perciben la transición a la plataforma digital. Se recogieron datos sobre una muestra de seis líderes de opinión y aproximadamente cien jóvenes universitarios para cumplir con el objetivo del estudio. El objetivo era conocer la opinión de la muestra, identificar las tendencias en relación a la transición de lo impreso para lo digital y captar sus percepciones acerca de la tecnología y las tendencias que se avecinan en el contexto brasilero. 
0

movimento provocado pela globalização e a pós-modernidade tem reverberado em todas as áreas do conhecimento, em especial na educação e na comunicação, refletindo enfaticamente no comportamento do homem atual. Vivemos, portanto, um novo momento, caracterizado por um movimento de profunda transformação, algo cíclico e comum na trajetória humana, no qual o homem tem a oportunidade de refletir e rever seu verdadeiro papel neste meio em que vive, percebendo o quanto pode atuar nele, assim como é influenciado por todas as mudanças e tendências impostas pela sociedade.

O cenário atual de profundas transformações impacta diretamente as organizações, que estão perdendo a centralidade diante de públicos opinativos e atuantes, que mobilizam as recentes redes sociais e os espaços públicos. Considerando uma realidade de inúmeros paradigmas e paradoxos que permeiam as organizações atuais, é possível perceber que vivemos num cenário de conflito entre passado e presente, seja em ambientes modernos ou pós-modernos. A busca, portanto, da melhor estratégia de relacionamento entre os públicos interno e externo apresenta-se como o mais recente desafio organizacional.

0 atual cenário globalizado, a consequente "extinção" das fronteiras geográficas e as profundas transformações decorrentes desse processo são vistos por Maria Aparecida Ferrari (2011) como oportunidade de mudança e de realinhamento de estratégias. Vista como corpo social, "um organismo vivo" (Morgan, 2011, p. 43), a organização passa a entender sua responsabilidade sobre as pessoas, seja o público interno ou o externo, com os quais deve naturalmente se relacionar e estabelecer conexões. Tais relacionamentos têm se mostrado cada vez mais abertos, por causa do advento da internet e das novas tecnologias. As mídias sociais no ciberespaço - como sites, blogues, Facebook, Twitter etc. - têm sido vistos como importantes canais de comunicação entre os públicos e as organizações.

No entanto, as organizações estão perdendo a centralidade e o poder da palavra está passando para as mãos das pessoas. Eric Schmidt e Jared Cohen (2013, p. 14) afirmam que, "no cenário mundial, o impacto mais significativo da difusão das tecnologias de comunicação será na maneira como elas ajudam a deslocar a concentração de poder para longe dos estados e [das] instituições, transferindo-a para os indivíduos". 0 referido processo envolve alto grau de risco para as empresas e as coloca num estado de vulnerabilidade constante, já que os canais de comunicação as expõem permanentemente de maneira positiva ou negativa. Ferrari (2011, p. 143) afirma até mesmo que "a vulnerabilidade a que estão expostas as organizações tem a força de impactar regiões, países e continentes".

Schmidt e Cohen (2013, p. 14-15) explicam esse cenário de "empoderamento" dos indivíduos, afirmando que

para alguns, a representatividade digital será a primeira experiência de poder em suas vidas, permitindo que eles sejam ouvidos, notados e levados a sério - e tudo graças a um aparelho que cabe no bolso. (...) Da maneira que a atual tecnologia de rede está estruturada, ela tende a favorecer o cidadão.

0 futuro, afinal, será articulado pelo modo como os estados, os cidadãos, e as organizações vão lidar com as novas responsabilidades, em posse desse novo poder de comunicação.

Na primeira parte deste artigo examinamos a revolução do impresso e a trajetória do mercado editorial brasileiro, os avanços eas inovações tecnológicas, que culminaram na criação dos livros digitais, ou e-books. Na segunda parte, discutimos o surgimento do homo zappiens, nascido na nova era digital, refletindo sobre a relação do hábito da leitura com o advento da internet e das novas plataformas digitais, levantando a questão da aceitabilidade dos e-books no Brasil, a disseminação do conhecimento e 
como a comunicação pode auxiliar na transição do impresso para o digital. 0 artigo é concluído com uma análise dos resultados obtidos na sondagem realizada em formato de constatações e controvérsias para servirem de agenda para futuras pesquisas.

\section{DO PAPEL AO VIRTUAL}

A comunicação humana, na modernidade, passou por uma grande transformação com o advento da tipografia, importante contribuição de Johannes Gutenberg (1400-1468), que entre 1425 e 1456 publicou a Bíblia com a ajuda de caracteres móveis, em uma tiragem de 180 exemplares, que foi o primeiro livro produzido na Europa. Gutenberg possibilitou, então, a revolução do conhecimento, com a propagação e acessibilidade à informação, antes dirigida apenas a um público seleto. Sua colaboração fez com que se multiplicasse a impressão de obras e escritos da época, barateando os custos, abrindo, assim, a era da comunicação social.

0 primeiro livro escrito, editado e impresso em terras brasileiras, por Luiz Antonio Rosado da Cunha, com trabalho tipográfico de Isidoro da Fonseca, trata da vinda do bispo D. António do Desterro Malheyro, que aportou no Rio de Janeiro em 1 º de dezembro de 1746 (Bragança; Abreu, 2008, p.26). Com a chegada da família real ao Brasil, em 1808, possibilitou-se também a criação da Impressão Régia, que impulsionou a publicação de livros, a princípio sobre atos oficiais, mas posteriormente com obras de interesse mais amplo, como a carta de Pero Vaz de Caminha sobre a descoberta do Brasil.

A partir do final do século XIX, dentre as obras de maior circulação, se destacam os livros escolares, aparecendo nesse cenário importantes editores, como Francisco Alves, Monteiro Lobato e a Companhia Editora Nacional.

Sandra Reimão (1996, p. 18-19) nos apresenta um panorama de três décadas importantes para o mercado editorial brasileiro, mostrando que os anos 1960 foram marcados por uma explosão qualitativa da fruição privada, os anos 1970, pelo crescente processo de industrialização da produção cultural e segmentação da cultura, e os anos 1980, pelo ecletismo e pelas oscilações nesse meio.

Superada a ditadura militar de 1964-1985, surgem novas editoras, de pequeno e grande porte, fusões de empresas e a entrada de grupos editoriais internacionais no mercado brasileiro, que procuram unir capital simbólico e econômico, transformando a edição de livros em algo rentável e de prestígio (Bragança; Abreu, 2008, p. 13). No entanto, apesar da diversidade e da proliferação de editoras nos últimos anos, não se verifica o aumento de tiragens e vendas, mas se constata a enorme participação do governo na compra de livros no país, especialmente os didáticos, por meio dos diversos programas de fomento à leitura (Bragança; Abreu, 2008, p. 14).

Com a chegada do século XXI, novos meios e novas linguagens foram sendo incorporados ao livro impresso, que ganhou dimensões sensoriais, olfativas, sonoras, lúdicas, além de seu ingresso no mundo da multimídia, por meio da utilização de CDs, DVDs e outros recursos que incrementaram as publicações de todos os gêneros e em especial as infantojuvenis.

No atual contexto das profundas e dinâmicas transformações contemporâneas, vivemos uma fase de transição entre 0 antigo e o novo mundo, o analógico e o digital, a carta impressa e a mensagem eletrônica, o telefone fixo e o celular, o celular e 
os smartphones (com internet e novíssimos recursos), o livro impresso e o e-book, os velhos sistemas e as revolucionárias plataformas, e-readers, tablets, iPad, Kindle, Kobo.

A questão da transição do meio impresso para o meio digital tem impactado profundamente o dia a dia das organizações, que convivem com múltiplas gerações dentro de seus ambientes e precisam se relacionar com todos, da melhor maneira possível, usando as plataformas acessíveis a cada um, incluindo aí os nascidos na era digital.

Wim Veen e Ben Vrakking ilustram bem o que seria esse "homo zappiens", o nativo digital, que convive com as outras gerações, dentro das organizações. Trata-se de "uma geração que faz as coisas de maneira diferente - um expoente das mudanças sociais relacionadas à globalização, à individualização e ao uso cada vez maior da tecnologia em nossa vida". Os pesquisadores sugerem "que olhemos para os valores dessa geração como uma fonte de inspiração e orientação para ajustarmos nossos sistemas educacionais ao melhor atendimento das necessidades de nossa sociedade futura" (Veen; Vrakking, 2009, p. 30).

No caso específico do livro impresso e do e-book, desde 2007, quando foi lançada nos Estados Unidos a primeira versão do e-reader (leitor de livro digital) Kindle, se criou no mercado editorial brasileiro uma polêmica segundo a qual o livro digital prevalecerá sobre o impresso, que se extinguirá dentro de pouco tempo. No entanto, os indícios apontados no presente estudo mostram outra direção: a convivência harmônica entre o impresso e o digital, durante ainda muito tempo.

Jason Epstein, responsável pela publicação de grandes escritores, como Gore Vidal e Philip Roth, e que atuou durante quarenta anos como diretor da Random House, uma das principais editoras em língua inglesa do mundo, analisa o mercado editorial internacional e oferece um importante testemunho sobre crise, conflitos e os impasses que esse meio apresenta. Epstein, no entanto, é taxativo quando afirma:

Hoje, a atividade editorial está à beira de uma grande transformação que promete muita oportunidade para inovar: muita tentativa, muito erro, muita melhora. Bem antes de outro meio século se passar, a indústria como eu a conheci nos últimos cinquenta anos terá sido alterada quase a um ponto irreconhecível (Epstein, 2002, p. 19-20).

Roger Chartier (2007), especialista em história da leitura, afirma que a internet pode se transformar em aliada dos textos por permitir sua divulgação em grande escala. Diferentemente dos que preveem o fim da leitura e dos livros por causa dos computadores, ele acha que a internet pode ser uma poderosa aliada para manter a cultura escrita.

A única pesquisa em âmbito nacional com o objetivo de avaliar o comportamento leitor do brasileiro foi realizada no Brasil em 2011 e promovida pelo Instituto Pró-livro (IPL), com o apoio da Associação Brasileira de Editores de Livros Escolares (Abrelivros), da Câmara Brasileira do Livro (CBL) e do Sindicato Nacional dos Editores de Livros (Snel). Essa pesquisa foi executada pelo Ibope Inteligência, com o apoio técnico do Centro Regional de Fomento ao Livro na América Latina e no Caribe (Cerlac), da Unesco. A amostra do estudo reúne a população brasileira com idade de cinco anos ou mais, o que compreendeu aproximadamente 178 milhões de pessoas. É importante ressaltar que, apesar dos avanços de leitura entre a população brasileira, o estudo constata que ainda não ultrapassamos os quatro livros por habitante/ano.

Extraída da pesquisa do Instituto Pró-Livro (IPL, 2011), observamos a análise do perfil do leitor de livro digital, considerando uma base de 9,5 milhões de usuários que já leram e-books. Verifica-se que a maioria desse público é formada por homens (52\%), 
entre 18 e 24 anos de idade (29\%), que possuem nível superior (43\%) e não estão estudando atualmente (51\%). Identifica-se também que os leitores de livro digital concentram-se nas classes A/B (53\%) e moram na região Sudeste do Brasil (47\%).

O comportamento do brasileiro em relação à internet foi investigado pela pesquisa do Instituto Pró-Livro (IPL, 2011), constatandose que $54 \%$ da população (178 milhões) não acessa a internet e a maioria desses se situa na faixa dos 50 anos ou mais. Os que acessam a internet diariamente representam $18 \%$ e a maioria está na faixa dos 18 a 29 anos. Interessante observar que os números atualizados da Agência Nacional de Telecomunicações (Anatel) mostravam que em março de 2014 o Brasil já contava com 273,58 milhões de celulares, ou seja, 1,34 celular por habitante, considerando que somos 203 milhões de brasileiros, segundo projeções do IBGE (maio de 2014). Nesse mesmo período, a banda larga móvel totalizou 114,42 milhões de acessos, dos quais 2,08 milhões eram terminais $4 G$.

Desta forma, parece haver uma contradição, pois se, de um lado, a leitura, seja por via impressa ou digital, ainda é baixa por habitante, a plataforma de celulares é utilizada por praticamente $100 \%$ da população. Com isso, podemos concluir que a mobilidade da informação e conectividade não está relacionada com o aumento da leitura. As pessoas se comunicam mais por celulares, mas não leem mais apesar das facilidades propiciadas pelas plataformas digitais.

Apesar de o mercado editorial nacional ter registrado, em 2012, o pior resultado da última década na venda de livros, a pesquisa "Produção e venda do mercado editorial", feita pela Fundação Instituto de Pesquisas Econômicas (Fipe) em 2013, por encomenda da Câmara Brasileira do Livro (CBL) e do Sindicato Nacional de Editores (Snel), apontou que o mercado de livros digitais cresceu mais de 350\% de 2011 para 2012, período em que estes realmente começaram a fazer parte da realidade do brasileiro. Apesar do aumento nas vendas, os e-books representam ainda cerca de $1 \%$ do faturamento das editoras no Brasil (Valeika, 2013). Segundo números divulgados pela CBL, a proporção de edições digitais não chega a 5\% (2014).

"Parece que a ideia do livro está tão profundamente enraizada no inconsciente coletivo que ninguém suporta deixá-la para trás", diz o jornalista David Streitfeld, em artigo no The New York Times. Streitfeld (2013) mostra como a inovação está no livro físico, não em e-books, afirmando que, ao mesmo tempo em que o universo dos textos impressos diminui, algumas das características mais conhecidas do livro revelam uma capacidade notável de continuarem vivas on-line. Prova disso são as inúmeras tentativas dos fabricantes de e-readers de tornarem o livro digital o mais parecido com o livro impresso, com recursos de som, que imitam o folhear da página, ou de luminosidade, que possibilita a opacidade de uma página impressa, por exemplo.

Mas o futuro próximo nos prepara novas surpresas. Enquanto nas bibliotecas brasileiras a adoção dos e-books ainda é insignificante, nos Estados Unidos foi inaugurada, em setembro de 2013, a primeira biblioteca pública do país sem livros físicos, no condado de Bexar, em San Antonio, no Texas. A BiblioTech empresta leitores de e-books, que custam ao governo US\$100 por unidade. São emprestados por duas semanas e depois disso param de funcionar. No Brasil, é difícil encontrar casos de biblioteca pública que oferece e-readers, mas temos, por exemplo, a Biblioteca de São Paulo, que desde 2010 oferece kindles para uso interno, sem empréstimo (Ventura, 2013).

Apesar de algumas previsões pessimistas vislumbrarem o fim dos veículos impressos (revistas e jornais) diante do atual crescimento do digital, há um consenso de que os meios de comunicação se adaptarão às mudanças tecnológicas e focarão seu trabalho no que realmente interessa: a produção de conteúdo, independentemente de qual plataforma for adotada - a impressa ou a digital. 0 comunicador, enfim, continuará a realizar seu trabalho de comunicar. 
No artigo "Por que seu cérebro prefere o papel", de Ferris Jabr (2014), a questão da aceitabilidade ou não das plataformas digitais toma outra dimensão e é analisada sob o olhar da neurociência. 0 autor destaca que,

\begin{abstract}
apesar de a tecnologia estar cada vez mais popular e acessível, a maioria dos estudos publicados desde o início da década de 1990 confirma as conclusões anteriores: o papel ainda oferece vantagens sobre a tela como meio de leitura. Reunidos, experimentos em laboratório, pesquisas e relatórios de consumo indicam que equipamentos digitais impedem as pessoas de navegar [por] textos longos de modo efetivo e podem sutilmente inibir a compreensão. Comparada ao papel, a tela pode exigir mais recursos mentais enquanto lemos e dificultar a fixação de lembranças sobre o que lemos. Conscientemente ou não, as pessoas se aproximam dos computadores e tablets com um estado mental menos aberto ao aprendizado que com o papel. Os e-readers também não conseguem reproduzir a experiência tátil da leitura em papel - e muitos se sentem desconfortáveis com isso (Jabr, 2014, p. 64).
\end{abstract}

Eric Schmidt e Jared Cohen (2013), ambos diretores do Google, apresentam um panorama do futuro próximo, tendo em vista que 0 acesso à internet e à telefonia móvel estará naturalmente disseminado pelos pontos mais isolados do planeta. Levantam questões polêmicas e procuram responder às possíveis mudanças no nosso cotidiano, nas áreas da economia, política, infraestrutura, segurança, social (doméstica, inclusive), entre outras, que mudarão profundamente toda a maneira como encaramos a vida e as relações interpessoais.

A análise desses profissionais mostra como a internet e as comunicações atribuirão poder aos indivíduos e transformarão o modo como as nações e as organizações funcionam hoje. A visão é de um futuro mais igualitário, com amplo senso de comunidade, claro, sempre considerando as escolhas que forem feitas no presente.

Nesses tempos pós-modernos, o uso das tecnologias de informação afeta todo o mercado de trabalho, as relações de negócios, as inter-relações pessoais e sociais, cobrindo grandes distâncias, mudando profundamente a forma de viver e de nos relacionarmos uns com os outros e com o mundo que nos cerca. Tais possibilidades nos remetem a diversas perguntas. Como os profissionais de comunicação poderão atuar de forma eficiente nesses novos tempos? Eles estão conscientes da importância de sua atuação nessa nova atualidade digital?

Cabemaquiduas proposiçõesaos profissionais decomunicação edeáreas afins. A primeira, de conscientizaçãodessadesafiadora fase de transição do impresso para o digital. A segunda, de preparação para esse futuro que os comunicadores inseridos no mercado de trabalho já estão vivenciando. Essa urgente adaptação se deve principalmente ao fato de que esses profissionais já necessitam executar tarefas múltiplas e diversificadas, com mobilidade, dinamismo, rapidez de respostas (especialmente na prevenção e gestão de crises organizacionais), com a exigência do domínio de todas as ferramentas e plataformas digitais disponíveis (como gerenciar o site da empresa, as mídias sociais, o Google AdWords ou o Google Analytics etc).

Tudo indica que novas experiências e oportunidades serão proporcionadas pela conectividade, que poderá trazer mais eficiência, conhecimento e qualidade de vida a todos. As possibilidades de atuação da área de comunicação na transição do meio impresso para o meio digital nos processos comunicacionais são inúmeras e muitas ainda a serem exploradas.

\title{
METODOLOGIA DE TRABALHO
}

Como comunicar-se com pessoas de diferentes faixas etárias e conhecimentos diversificados em uma mesma organização? Como abordar públicos interno e externo, acompanhando as mudanças de linguagem e forma adotados pela grande maioria das empresas, em diferentes dimensões? 
Com o objetivo de auxiliar a busca de respostas para as questões apresentadas, sobre a transição do meio impresso para o meio digital nos diferentes cenários, foram elaborados alguns pressupostos para serem testados na sondagem realizada:

- $\quad$ Os jovens tendem a desfrutar das novas tecnologias com frequência e utilizam menos as mídias impressas.

- A presença de gerações distintas numa mesma organização interfere na forma como a empresa se comunica interna e externamente.

- $\quad 0$ trabalho de comunicação numa organização pode estabelecer convergência da mensagem a ser transmitida pelas plataformas disponíveis aos diferentes públicos (interno e externo), para se adaptar aos diferentes perfis.

- As mídias impressas e as digitais podem coexistir harmonicamente dentro das organizações e em diferentes esferas da sociedade.

Buscando levantar informações e identificar as tendências em relação ao tema da transição do impresso para o digital, foi aplicada uma sondagem a seis líderes de opinião e aproximadamente cem estudantes universitários, visando identificar e analisar a percepção que ambos os públicos tinham da tecnologia e, em seguida, refletir sobre tendências que se avizinham.

Foram convidados profissionais que, de alguma forma, se relacionavam com o mundo da comunicação e do livro para opinarem com mais propriedade sobre o tema deste estudo. Responderam ao nosso chamado seis líderes de opinião, a saber: Celso Kinjô, editor da revista Negócios da Comunicação, que pesquisa a transição do impresso para o digital nos veículos de comunicação e as novas linguagens nessa área; Karine Pansa, presidente da Câmara Brasileira do Livro (CBL), instituição que normatiza 0 mercado editorial, para tratar especialmente da transição do livro impresso para o livro digital; Luiz Felipe Pondé, filósofo e professor da Pontifícia Universidade Católica de São Paulo (PUC-SP) e da Fundação Armando Álvares Penteado (FAAP), para focalizar as questões que envolvem a aceitabilidade ou não das novas tecnologias; Milton Jung, jornalista, que viveu a transição das antigas redações de jornais para as novas linguagens e que atua como âncora da Rádio CBN e está envolvido com as inovações digitais no veículo rádio; Raphael Barreto, publicitário, indicado para o Prêmio Caboré 2013, vice-presidente de Planejamento da Foote, Cone \& Belding (FCB Brasil), agência de propaganda presente em quase cem países e entre as dez maiores agências digitais do Brasil, que foi um dos idealizadores da campanha "Leia para uma criança", da Fundação Itaú Social, a qual distribuiu gratuitamente mais de 35 milhões de livros infantis até 2014; J. W. M. Pires, o Pipol, coordenador do Cronópios, um portal que promove cultura, literatura e entretenimento e explora recursos digitais avançados. Para os seis profissionais foi encaminhado por e-mail um roteiro de entrevista com dez questões abertas.

Para conhecer a opinião dos jovens universitários, público que acreditamos estar conectado de forma direta ao mundo digital e às inovações tecnológicas, foram escolhidos os alunos do curso de graduação em Relações Públicas, da Escola de Comunicações e Arte da Universidade de São Paulo (ECA-USP). Foi elaborado um questionário com questões fechadas, entregue em papel e respondido de forma anônima; dos 230 alunos regularmente matriculados, aproximadamente 100 $(42,6 \%)$ responderam o instrumento. 


\section{RESULTADOS OBTIDOS}

Os resultados obtidos foram estruturados em 'constatações' e 'controvérsias'. Interessante observar que algumas das respostas do grupo de líderes apresentaram similaridade com as dos jovens estudantes da USP, confirmando alguns conceitos e formas de pensar e estabelecendo tendências nessa fase de transição do meio impresso para o meio digital.

As constatações advindas do cruzamento dos resultados da pesquisa confirmaram a premissa de que as novas tecnologias significaram uma ruptura nos modelos tradicionais de comunicação e na forma como nos comunicamos. Os dois grupos apresentam-se confortáveis com as inovações tecnológicas e parecem explorá-las em suas vidas pessoal e profissional.

No entanto, estudantes e especialistas, em sua maioria, nunca leram um e-book e dizem preferir o livro impresso. Dos líderes de opinião, alguns já leram livros digitais, por questões profissionais ou práticas, mas confessam a preferência pelo impresso.

A segunda constatação aponta que o livro impresso causa uma experiência sensorial, tátil, que ainda não é possível encontrar no formato do livro digital. 0 e-bookparece trazer uma impessoalidade, um não-pertencimento e uma não-existência que incomoda os dois grupos, apesar de o senso comum defender que as gerações mais jovens abraçam a tecnologia de forma incondicional.

0 fato de os jovens, de 18 a 22 anos, ainda preferirem o livro impresso em detrimento do digital prova que a relação pessoal com o 'objeto livro' é forte, apesar de identificarmos, pelos resultados, que a leitura não é um fator de suma importância para os universitários sondados.

A leitura representa conceitos bem diferentes para os dois grupos. Os líderes têm uma percepção mais sensorial e afetiva com o livro e os universitários veem a leitura como algo aparentemente mais prático e talvez um pouco distante e menos afetiva. Porém, ambos os grupos concordam, em sua maioria, com a coexistência harmoniosa do livro impresso e do digital, que se dará por um longo período de tempo. Com relação aos veículos de comunicação impressos - revistas e jornais -, há uma tendência de que o digital prevaleça, uma vez que se trata de informação temporal, para a qual o meio digital está mais preparado para oferecer informações em tempo real.

Por outro lado, a primeira controvérsia que aparece entre líderes de opinião e universitários está relacionada ao preço do e-book no Brasil; segundo os alunos, o custo do e-book é muito alto, enquanto os líderes de opinião não sinalizam esse fator como importante, e para eles há outras barreiras além do preço para a opção da leitura digital.

A segunda controvérsia mostra que estamos longe do tempo em que o digital prevalecerá sobre o impresso e será a única opção de plataforma de leitura e disponibilização de conteúdo. Os dois grupos - os estudantes e os líderes de opinião - são unânimes em determinar que a "era 100\% digital" ainda tardará a chegar. As plataformas digitais para leitura de livros ou de textos longos ainda apresentam inúmeras desvantagens, que remetem ao cansaço físico (visual), ao não-pertencimento do objeto digital ou à sua não-existência (já que o e-booknão é palpável), à falta de contato físico e ritualístico como ocorre com o livro impresso, que tem cheiro, possibilita o folhear das páginas e o progresso da leitura.

No caso específico do objeto livro impresso, Karine Pansa, presidente da CBL, prevê que "tanto o livro impresso como o digital ocuparão um lugar distinto no hábito de leitura das pessoas". Talvez esse "lugar distinto" possa ser o mesmo lugar em que 
estamos hoje, onde convivemos com LPs (vinil) e CDs, DVDs e Blu-ray, tevê a cabo e tevê aberta, cinema e DVD, entre outras plataformas que coexistem harmoniosamente e estão direcionadas para públicos de diferentes perfis e poder aquisitivo.

\section{CONSIDERAÇÕES FINAIS}

0 tema sobre o futuro do livro impresso tem sido discutido incansavelmente em congressos e eventos promovidos por instituições ligadas ao mercado editorial e às novas tecnologias, além de universidades do mundo todo. Muitos profissionais desse meio defendem a ideia de que o livro em papel será extinto e o digital prevalecerá como plataforma principal dos leitores.

A pesquisa apresentada traz uma luz para essa questão, mesmo sendo apenas uma sondagem. Os resultados dessa sondagem com líderes de opinião e universitários demonstram uma inevitável coexistência entre o meio impresso e o digital, de forma harmônica e longeva. É inegável que a internet veio estabelecer uma ruptura de paradigmas que atinge todas as áreas da nossa existência. Hoje, somos mais conectados e mais próximos. A tecnologia tem trabalhado a favor das pessoas que encaram, pela primeira vez, um 'empoderamento' inexistente há algum tempo.

0 poder centralizado que se encontra em mãos de poucos está com seus dias contados. A manipulação e o poder político encontram seu fim, num cenário no qual as pessoas conhecem seus direitos e as infinitas possibilidades de ser. Vemos a expansão do conhecimento, que regenera e nutre a todos, de maneira incondicional e justa, sem distinção de classe social, raça ou qualquer atributo criado pelo relativismo humano. 0 conhecimento está disponibilizado cada vez mais de forma fluida e abrangente, em distâncias físicas que tendem a desaparecer pela proximidade provocada pelas ligações virtuais. A tecnologia trabalha a favor da disseminação desse conhecimento, que liberta as pessoas e amplia a visão do mundo ao seu redor.

Com mais de um celular por habitante, o brasileiro demonstra o desejo de se comunicar, de estabelecer conexão com seus parese ampliar seus próprios limites, seja explorando as plataformas digitais ou no trabalho interno de cada um, na plataforma humana.

Estamos num caminho sem volta e teremos que trilhá-lo da melhor forma possível. Não há como ignorar sua interferência na vida de cada um. As organizações, como as pessoas, também estão sendo afetadas por essas grandes transformações.

Este estudo pretendeu refletir sobre a transição do meio impresso para o meio digital, ressaltando a adaptabilidade da mensagem para os variados públicos de relacionamento e as diversas plataformas adotadas, promovendo o estreitamento entre gerações anteriores e a nova geração nascida na era digital, acostumada com a linguagem da internet e dos meios disponíveis na atualidade, como sites, blogues, intranet, newsletters, mural eletrônico, redes sociais, aplicativos para celulares e tablets etc.

Apesar da aparente revolução das plataformas digitais e de suas linguagens, inseridas num contexto de comportamento presumivelmente pós-moderno (caracterizado pela explosão das novas tecnologias), as gerações atuais, mesmo os jovens na faixa dos vinte anos, ainda utilizam meios impressos e demonstram uma aparente aversão a algumas tecnologias, como os leitores de livros digitais, os chamados e-readers, como Kindle e o Kobo, e os tablets, como o iPad, entre outros, ainda preferindo a leitura de livros impressos. 
Talvez, como já aconteceu com diversas transições tecnológicas, viveremos a coexistência dos dois meios ou o impresso será representado por produtos diferenciados. Ou ainda, será que não viveremos essa transição como uma não-transição, uma nova realidade, assim como ocorreu com a tevê a cabo e a tevê aberta, que coexistem atualmente e são dirigidas a públicos diferentes? Ou como a tevê a cabo e o cinema, que oferecem duas opções do mesmo produto em formatos distintos? Alguns desses, inclusive, já oferecem, há tempos, recursos como a interatividade ou o pay-per-view, no qual o assinante seleciona o filme que quer assistir na hora que escolher. E o que dizer da transição LP (vinil)/CD/MP3 e tantos outros formatos de arquivos de áudio e vídeo?

Nós já estamos nesse caminho. Já acabou a era da massificação e de produtos padronizados. Vivemos a era dos produtos segmentados, respeitando a diversidade, a individualidade e as diferenças de preferências dos públicos, gostos e necessidades pessoais e de saúde.

Cada vez mais, serão disponibilizadas inúmeras opções para as pessoas - que antigamente não tinham o poder de escolha -, seja na alimentação, no entretenimento, na cultura, na estrutura, no formato e na plataforma de leitura, de acordo com suas preferências e condições. Se essa pessoa vai comprar um Kindle para ler um livro digital ou recorrerá ao sebo mais próximo da sua casa para adquirir um livro impresso, o que realmente importa é que o conhecimento estará disponível, seja da forma que for, para todos os públicos e em diferentes formatos.

Uma questão continua a ser levantada: será que conseguiremos, enfim, viver numa sociedade cem por cento digital? Talvez isso só possa acontecer quando as pessoas nascerem no seio de 'famílias digitais', que não tenham se relacionado com as referências dos meios impressos. Mas isso levará ainda muito tempo. Enquanto isso, a realidade digital nos convida a experimentar as infinitas possibilidades de comunicação - communicare, tornar comum, partilhar -, de meios que estão à nossa disposição, para que tenhamos todas as experiências possíveis, visando à nossa própria evolução e ao nosso aperfeiçoamento.

\section{REFERÊNCIAS}

BRAGANÇA, Anibal; ABREU, Márcia (Org.). Impresso no Brasil: dois séculos de livros brasileiros. São Paulo: Editora Unesp, 2008.

CHARTIER, Roger. Os livros resistirão às tecnologias digitais. [Depoimento a Cristina Zahar]. Revista Nova Escola, São Paulo, Editora Abril, ago. 2007, n. 204. Fundação Victor Civita. Disponível em: <http://revistaescola.abril.com.br/ lingua-portuguesa/ fundamentos/roger-chartier-livros-resistirao-tecnologias-digitais-610077.shtml?page=all>. Acesso em: 20 fev. 2014.

EPSTEIN, Jason. O negócio do livro: passado, presente e futuro do mercado editorial. Trad. de Zaida Maldonado. Rio de Janeiro: Editora Record, 2002.

FERRARI, Maria Aparecida. Os cenários turbulentos como oportunidade de mudança e de realinhamento de estratégias. In: GRUNIG, James E.; FERRARI, Maria Aparecida; FRANÇA, Fábio. Relações públicas. teoria, contexto e relacionamentos. 2. ed. rev. e ampl. São Caetano do Sul, SP: Difusão Editora, 2011.

IPL - INSTITUTOPRÓ-LIVRO. Retratos da leitura no Brasil. 3. ed. São Paulo: Imprensa Oficial: 2011. II Seminário Nacional, 28 de março de 2012. Brasília, DF. Disponível em: <http://www.prolivro.org.br/ipl/publier4.0/dados/anexos/2834_10.pdf>. Acesso em: 24 fev. 2014. 
JABR, Ferris. Por que seu cérebro prefere o papel. Revista Mente e Cérebro, São Paulo, Duetto Editorial, a. XX, n. 256, p.62-69, maio 2014.

MORGAN, Gareth. Imagens da organização. Trad. de Cecília Whitaker Bergamini e Roberto Coda. São Paulo: Editora Atlas, 2011.

REIMÃO, Sandra. Mercado editorial brasileiro. São Paulo: Com-Arte: Fapesp, 1996.

SCHMIDT, Eric; COHEN, Jared. A nova era digital: como será o futuro das pessoas, das nações e dos negócios. Trad. de Ana Beatriz e Rogério Durst. Rio de Janeiro: Intrínseca, 2013.

STREITFELD, David (New York Times). Manifesto diz que inovação está no livro físico, não em e-books. Folha de S.Paulo, 17 dez. 2013. Disponível em: <http://wwwl.folha.uol.com.br/tec/2013/12/1385447-manifesto-diz-que-inovacao-esta-no-livro-fisiconao-em-e-books.shtml>. Acesso em: 17 dez. 2013.

VALEIKA, Fernando. Mercado editorial encolhe, mas e-books crescem 343\%. Revista Veja, Editora Abril, 31 jul. 2013. Disponível em: <http://veja.abril.com.br/noticia/entretenimento/mercado-editorial-encolhe-mas-e-books-crescem-343>. Acesso em: 10 jan. 2014.

VEEN, Wim; VRAKKING, Ben. Homo zappiens: educando na era digital. Trad. de Vinicius Figueira. Porto Alegre: Artmed, 2009.

VENTURA, Felipe. Primeira biblioteca pública dos EUA sem livros físicos emprestará leitores de e-book. Site Gizmodo Brasil, 14 de janeiro de 2013. Disponível em: <http://m.gizmodo.uol.com.br/primeira-biblioteca-publica-dos-eua-sem-livros-fisicosemprestara-leitores-de-e-book/>. Acesso em: 23 jan. 2014. Baseado no artigo de GONZALEZ, John W. Bexar set to turn the page on idea of books in libraries. 11 de janeiro de 2013. Site MySA (San Antonio's home page). San Antonio, Texas, USA. Disponível em: <http://www.mysanantonio.com/news/local_news/article/Bexar-set-to-turn-the-page-on-idea-of-books-in-4184940.php>. Acesso em: 22 jan. 2014.

Artigo recebido em 02.09.2014 e aprovado em 10.10.2014. 